\title{
LA DISPUTA FINANCIERA POR EL IMPERIO DE MAXIMILIANO Y LOS PROYECTOS DE FUNDACIÓN DE INSTITUCIONES DE CRÉDITO (1863-1867)
}

Leonor Ludiow

Universidad Nacional Autónoma de México

LA HISTORIOGRAFÍA SOBRE EL PERIODO DEL segundo imperio en México (1863-1867) preserva gran parte de las versiones y razones que construyó la fracción del liberalismo decimonónico, enfatizando sobremanera las ambiciones internacionales en combinación con las traiciones de la "reacción mexicana", ocupada en la preservación del antiguo orden. El carácter de gobierno usurpador y su brevedad han llevado incluso, a considerar el periodo imperial como inexistente, como lo muestran varios manuales de historia de nuestros días, en los que están ausentes esos años a diferencia de las detalladas narraciones de hechos que permiten destacar la valentía y convicción de las fuerzas liberales encabezadas por el presidente Juárez.

Me parece necesario dejar a un lado las visiones sectarias con el fin de alcanzar un análisis y balance más equilibrado de la razón de ser del imperio, y de su impacto en el proceso posterior que heredó estructuras y prácticas económicas imperiales. Ya que durante ese periodo se inició un proceso de recomposición de las familias políticas y financieras del periodo interior, con el consiguiente reacomodo de las élites del dinero que paulatinamente abandonaron el jugoso y especulativo campo del crédito público para adentrarse en la promoción de inversiones en los sectores mercantil, productivo y de infraestructura, como quedó de manifiesto en los años de la restauración republicana enca- 
bezada por los presidentes Benito Juárez y Sebastián Lerdo de Tejada.

Este texto tiene el objeto de analizar las diferentes estrategias de crédito de poderosos grupos financieros europeos que concurrieron sobre la empresa imperial mexicana durante el primer año de vida del régimen de Maximiliano (1864). Sobre los cuales se impuso el pragmatismo inglés no obstante el dominio diplomático militar del gobierno francés de Bonaparte, como se aprecia en el manejo de las finanzas, la política de comunicaciones y de colonización que sobrevivió a través de varias empresas, como fue el Banco de Londres, México y Sudamérica que funcionó sin cambio alguno hasta fines de los años 1880 .

I

Se debe recordar que el segundo imperio formó parte de las primeras políticas de expansiones económica y territorial que caracterizaron la primera etapa de los imperialismos inglés y francés de los años 1860. De tal forma que el retiro de las tropas inglesas del puerto de Veracruz, en abril de 1862, no significó que los financieros y comerciantes británicos abandonaran los reclamos presentados por sus súbditos en la Convención inglesa, ni por los tenedores de bonos de los préstamos concedidos a los primeros gobiernos independientes por la banca inglesa. Los ingleses buscaron diversas vías para mantener el dominio que desde antes de la guerra de independencia alcanzaron a tener en diversos sectores de la economía mexicana, como el control del comercio de minerales y la circulación monetaria, además de su fuerte participación en el comercio exterior y en el crédito público.

El representante inglés Charles Lennox Wyke logró, por la vía diplomática, satisfacer parte de sus intereses, al obtener una promesa del gobierno juarista para formar una comisión que diera inmediata solución a esos reclamos. Eso quedaba demostrado en la entrega de recursos que durante 1861 se hizo de bienes del clero o con los ingresos 
obtenidos por la venta de propiedades desamortizadas, como lo ejemplificaban los acuerdos establecidos con Nathaniel Davidson, representante de las ramas inglesa y francesa de la banca europea de la familia Rothschild ${ }^{1} \longrightarrow$ o los pagos cubiertos a la poderosa firma mercantil anglosajona de Barron y Forbes. ${ }^{2}$

Pero al mismo tiempo fue garantía importante para los intereses británicos el hecho de que las tropas francesas permanecieran en tierras mexicanas en virtud de la alianza anglofrancesa que desde la guerra de Crimea se había expresado entre algunos grupos políticos en los ámbitos político, militar y financiero. ${ }^{3}$

La colaboración entre estas naciones fue recomendada por el consejero imperial Michel Chevalier al emperador Bonaparte, en su texto Le Mexique, Ancien et Moderne señalaba la necesidad de establecer "Un buen acuerdo entre las dos naciones más poderosas del globo [...] [dada] la concordancia de ópticas sobre los principales acontecimientos y sobre el mercado general de los negocios". ${ }^{4}$

Hay que recordar que los gobiernos de Bonaparte II y de la reina Victoria manifestaron una clara vocación imperial

${ }^{1}$ En las primeras ofertas que se le hicieron a Maximiliano para que aceptase el cargo, se prometió conseguir un préstamo por 25000000 de pesos mexicanos "[...] para cuya obtención podía mediar la casa Rothschild y el que había que procurar que participasen, además de financieros franceses, financieros ingleses", ConTe, 1944, pp. 106 y 111.

${ }^{2}$ Los arreglos y cálculos de los adeudos con los ingleses fueron compilados por PAYNo, 1982, pp. 1-140. La correspondencia de Davidson con la dirección de la firma es la fuente principal del artículo de GiLLe, 1965. La narración del préstamo de Miramar y el crédito que se pidió en 1864, en LEFÊBRE, 1869, vol. II, pp. 143-206.

${ }^{3}$ El historiador inglés George Macaulay Trevelyan considera que esta alianza fue estratégica para los ingleses dadas las ambiciones expansionistas de Bonaparte II, pero señala que a pesar de los buenos oficios del ministro de Asuntos Extranjeros, Lord Palmerston "[...] los ingleses siempre fueron incrédulos", Cotтrel, 1984, p. 470. Asimismo, afirma que a pesar de los avances de expansión financiera de los franceses, debieron quedar "bajo la dependencia de Inglaterra", dada su experiencia y amplitud de relaciones al interior y exterior de Europa, CoTtrel, 1984, pp. 178-179.

\footnotetext{
${ }^{4}$ Chevaluer, 1863 , p. 496.
} 
al ser partícipes activos en la reconstitución de los territorios europeos y mediterráneos ocurrida durante esa época de "formación de naciones". El dominio de ingleses y franceses se tradujo en abiertas expansiones económica y financiera hacia diversas regiones del mundo como Egipto o Turquía y China, así como en Argentina, Brasil y México; la colaboración no fue ajena a conflictos entre ingleses y franceses como ocurrió durante la unificación italiana y la relación con el vecino austríaco, y más adelante por el avance del poderío prusiano encabezado por el canciller Bismarck. ${ }^{5}$

La combinación de los intereses financieros en Londres y París fue parte importante de esa alianza diplomática militar entablada entre los respectivos gobiernos, y entre ellas destaca la colaboración en países como Austria o Egipto (la construcción del canal de Suez) por parte de las casas inglesas de Baring con la firma Crédit Mobilier de Isaac Pereire, quien fue le banquero favorito del régimen bonapartista. ${ }^{6}$

Los acuerdos entre la Francia de Bonaparte y la España isabelina no fueron menos importantes en la decisión de formar la Alianza Tripartita contra el gobierno juarista. De una parte, estas naciones y Austria ${ }^{7}$ estuvieron a favor de la política pontificia en el proceso de unificación italiana,

${ }^{5}$ Chevalier, 1863 y Girarad, 1986, pp. 275-292.

${ }^{6} \mathrm{G}_{\mathrm{IRARAD}}, 1986$, pp. 210-212; acerca de las relaciones de estos grupos con Bonaparte véase Bolvier, 1992, p. 111. También en Pi.sssis, 1979, pp. 110-112.

${ }^{7}$ Las relaciones financieras con Austria se establecieron mediante la intervención del banquero francés Archile Fould, en B. Gil.i E, 1970, pp. 170-173 y 182. Un estudio completo sobre esta colaboración a través del Anglo Osterrischische Bank, en Michel, 1977, pp. 228-233.

${ }^{8}$ El equilibrio europeo del decenio de 1850 comprendía igualmente a las alianzas con el papado, en especial, por el apoyo franco-austriaco para devolver al papa Pío IX su residencia en la ciudad de Roma, combinación que fue un factor importante para atender las demandas de los ultramontanos mexicanos e inclinarse por Maximiliano de Habsburgo dado su rasgo de príncipe católico. Sobre este punto, Chevalier dedica un capítulo especial en el que explica al emperador los pros y contras de las presiones del catolicismo mexicano en la empresa imperial, apartado que lleva por título: La tentative de régénerer le Mexique, considérée dans ses rapports avec l'attitude actuelle de la Cour de Rome, vis-à vis de la civilisation moderne, en Chevalier, 1863, pp. 543-597. 
pero además, en el ámbito europeo sobre estas naciones pesaba igualmente la influencia de la dinastía de los Rothschild a través de sus ramas francesa y austriaca, así como por los lazos financieros que la primera mantenía con el régimen español del que había recibido, desde principios del siglo XIX, el derecho a explotar las minas de azogue de Almadén, ${ }^{9}$ lo que le permitió a este emporio europeo mantener el monopolio mundial de este producto, indispensable para la producción argentífera.

Las viejas alianzas establecidas desde los días de la Santa Alianza entre esta potencia financiera europea y los citados gobiernos, explica el porqué de la selección de un príncipe austríaco católico para gobernar a México. Decisión que políticamente justificó el consejero político, Michel Chevalier, en la necesidad de sumar los intereses españoles en parte por la influencia de España sobre su antigua colonia lo que permitiría constituir una firme alianza entre naciones latinas y católicas que deberían hacer frente a los avances anglosajón y protestante. ${ }^{10}$

En términos económicos y de corto plazo el expansionismo bonapartista prometió, a los capitales franceses y a sus aliados europeos, abrir las puertas a sectores clave de la economía mexicana, como era el "[...] crédito público, el establecimiento de una Banca Nacional, los ferrocarriles y las minas"." Lo cual resultaba muy prometedor en ese momento, dada la relativa parálisis de los negocios parisinos durante 1860-1861 como resultado de la aplicación del librecambismo que provocó una baja en los ingresos aduanales, y como consecuencia de los altos costos de las intervenciones militares en Roma y en China, que terminaron por desnivelar el presupesto imperial. ${ }^{12}$

Pero las promisorias alianzas mercantiles y financieras prometidas entre inversionistas ingleses, franceses y españoles sólo pudieron realizarse en algunos renglones, como

\footnotetext{
${ }^{9}$ Bouvier, 1992, pp. 144-149 y 166-169.

${ }^{10}$ Chevalier, 1863, pp. 497-499.

${ }^{1}$ G. Gllte, 1965, p. 194.

1 'ªrbier, 1991, p. 204.
} 
la ampliación de los intercambios directos entre los puertos franceses y españoles con los mexicanos. ${ }^{13}$ Otro terreno de colaboración fueron los créditos concedidos al imperio de Maximiliano por casas bancarias y bancos londinenses y parisinos. ${ }^{14}$ Además, en agosto de 1864 se traspasó la concesión de la Compañía Imperial a inversionistas británicos para terminar de construir el primer ferrocarril entre la ciudad de México y el puerto de Veracruz. ${ }^{15}$ Sin embargo, no fue posible lograr la colaboración en otros sectores donde se registró un fuerte conflicto de intereses como ocurrió en el manejo y distribución de los ingresos aduanales, en la venta de las propiedades eclesiásticas y en las empresas de colonización.

La competencia entre franceses e ingleses, una vez que quedaron a un lado los intereses y reclamos de los residentes españoles, se extendió al gobierno imperial cuyos exiguos recursos fueron disputados por las cabezas militar y financiera que Bonaparte envió a México para dirigir las finanzas y el ejército invasor; tensiones y desacuerdos que se agudizaron a medida que el endeudamien to de la administración de Maximiliano iba en aumento, y en tanto que la promesa de abundantes recursos fiscales desaparecía por la imposibilidad de las tropas imperiales de controlar el territorio mexicano. ${ }^{16}$

${ }^{19}$ Véase CADIER, 1991, pp. 205-212, véanse, además, los textos de $\mathrm{M}_{\mathrm{AI}}-$ LLeFERT, 1992, pp. 165-167 y ArNaud, 1891, p. 36.

${ }^{14}$ En G. Gille, 1965, pp. 200-214.

${ }^{15}$ Chapman, 1975, pp. 103-108 y G. Gille, 1965, pp. 243-248.

${ }^{16} \mathrm{~A}$ pesar de los constantes movimientos de tropas se mantuvieron controladas bajo el orden imperial las ciudades de Zacatecas, San Luis Potosí, Guanajuato, Querétaro, Guadalajara, Morelia, México, Toluca y Puebla, algunas plazas en el sur y en la región del Golfo, como las de Orizaba, Córdoba, Tehuacán, Teotilán, Yahutatla y Oaxaca, junto a los puertos de Guaymas, Tampico, Tuxpan, Veracruz, Manzanillo, Tepic, Acapulco y Mazatlán y los puntos fronterizos de Piedras Negras y Reynosa en Tamaulipas, en Chevalier, 1965, pp. 9-25. 
En el ámbito financiero hubo una franca colaboración entre inversionistas franceses e ingleses, según ha mostrado la historiadora francesa Geneviève Gille, cooperación que se extendió al sector de las iniciativas que presentaron estos grupos para establecer el primer banco del país. Entre 1863-1864 se presentaron ante la Regencia, Maximiliano y Bonaparte, varios proyectos para fundar instituciones de crédito, promovidos por asociaciones financieras anglo-francesas que buscaron la concesión gubernamental en materia bancaria, lo que se traduciría en privilegios de diferente naturaleza, consistentes en la concesión del monopolio de la emisión, la libre circulación de billetes en todo el territorio nacional, el manejo en el comercio de la plata y el papel de agente financiero del erario hasta el no pago de impuestos o la dotación de terrenos para la construcción del inmueble.

Las iniciativas presentadas por los sindicatos anglofranceses tuvieron rasgos y metas comunes, propias de la creciente expansión financiera que en forma conjunta llevaban a cabo comerciantes de materias primas, casas bancarias e instituciones de crédito radicadas en las ciudades de Londres y París, quienes reforzaban sus iniciativas con los respectivos gobiernos y cabezas del ejército garantes de la expansión político-militar en algunas regiones. ${ }^{17}$

La colaboración entre comerciantes y financieros era factible en la medida en que sus objetivos eran complementarios ya que unos iban en pos del control del comercio de materias primas y de alimentos, en tanto que los otros les procuraban parte de los recursos y mecanismos de pago en zonas lejanas, donde optaron, preferentemente, por establecer agencias o filiales de banca colonial, buscando con ello " $[\ldots]$ ofrecer servicios bancarios

${ }^{17}$ Youssef Cassis, afirma que la segunda expansión de la llamāa banca colonial (o "anglo-foreign banks") se registró de 1860-1870, y su éxito se debió fundamentalmente a su relación con las finanzas internacionales, y en algunos casos de la Foreign Office, en Cissis, 1987, p. 37. 
a los negociantes que operaban en regiones nuevas, en las cuales se carecía de infraestructuras crediticias, pero además, tales establecimientos se beneficiaban de esta situación atrayendo como sus clientes a las clases acomodadas nativas". 18

El modelo franco-inglés de banca colonial en ese periodo se implantó en diversas regiones del mundo, con el objeto de concentrar y modernizar las relaciones financieras entre el viejo continente y algunos países localizados en África, Asia y América Latina, víctimas del rezago bancario, pero provistos de materias primas y de alimentos demandados en Europa, o en otras zonas del planeta, al alcanzar con esto el monopolio de la comercialización de productos como los metales preciosos e industriales, de insumos y alimentos, como el café y el azúcar entre otros.

De esta forma, estas instituciones fueron intermediarias de préstamos extranjeros con el fin de dar fuerza a las estructuras hacendísticas de gobiernos nacionales o coloniales, necesitados de recursos dada la dificultad en obtener suficientes fondos por medio del fisco. Asimismo, mediante la creación de bancas, los mercaderes europeos lograron asegurarse el manejo de determinados centros productivos agrícolas y mineros sin necesidad de desembolsar capitales para abrir nuevos centros, ya que gracias a los bancos lograron dominar o influir, al menos en el comercio de estos bienes.

Lo anterior queda de manifiesto en los cuatro proyectos bancarios localizados hasta ahora, los cuales tienen varios rasgos en común según se aprecia en el cuadro de la siguiente página. Estos proyectos coincidían con los lincamientos presentados por comerciantes y agiotistas mexicanos desde mediados del siglo XIX, con el fin de dar aliento al comercio, pero también se intentó crear una banca de gobierno. Todos estos proyectos marcaban un cambio en la vida mercantil y crediticia mexicana, en la medida en que se trataba de fundar establecimientos modernos, acordes

${ }^{18}$ Cassis, 1987. 


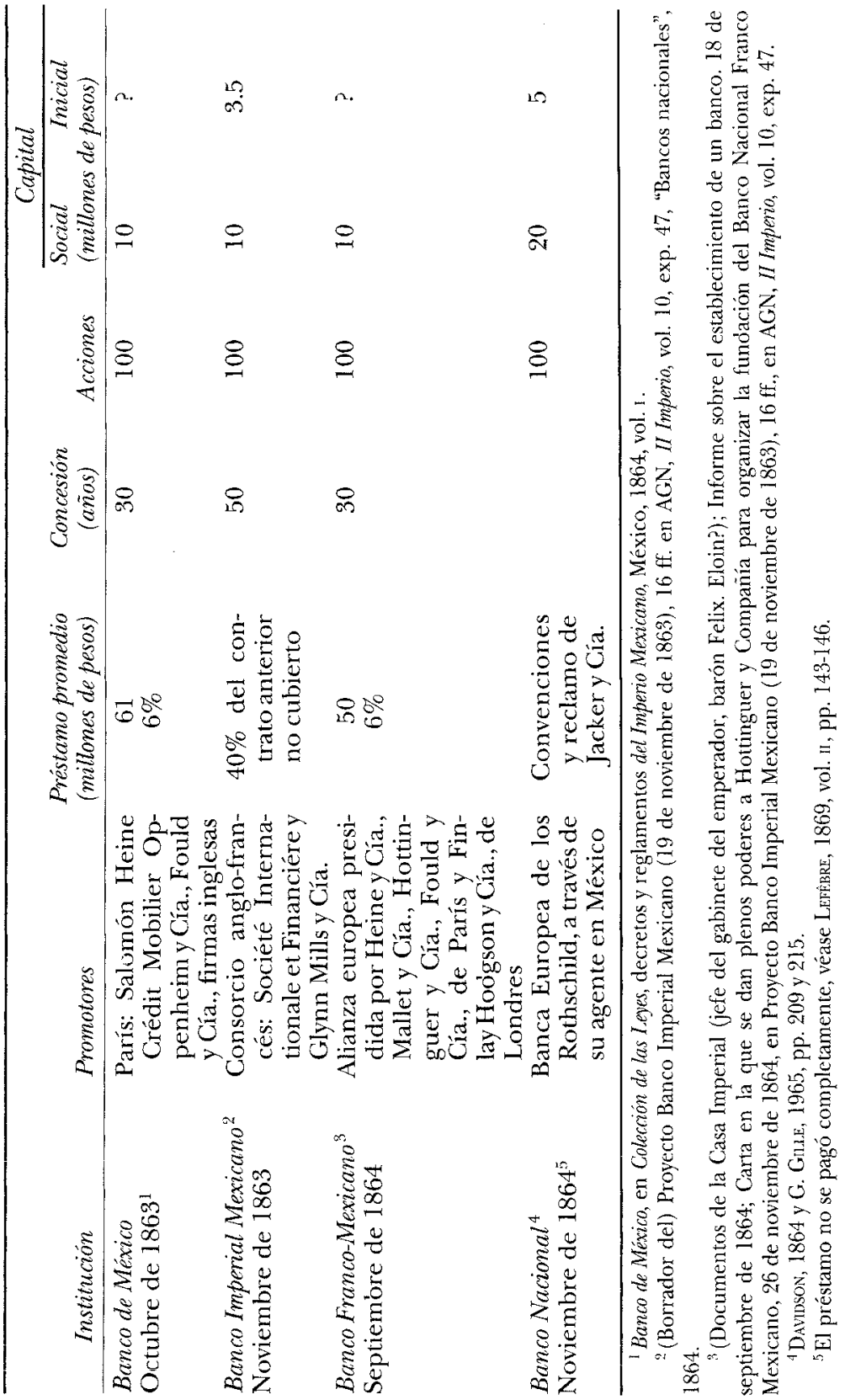


con el dinamismo mercantil entre algunas plazas y con el exterior. ${ }^{19}$

Tres de los cuatro proyectos presentados ante las autoridades mexicanas o francesas en 1864, fueron respaldados por un préstamo. Promesa excelente para que las propuestas bancarias fueran bien recibidas por los respectivos gobiernos por el estado de bancarrota de la Hacienda Pública. Este tipo de propuestas presentadas en México - y en otros países- eran complementarias para los objetivos expansionistas de los financieros europeos ya que la futura institución de crédito, además de ser el canal propio del crédito ofrecido, recibiría diferentes privilegios y prebendas, al demandar: $a$ ) el rango de única institución de crédito por varias décadas; $b$ ) la prerrogativa del monopolio de la emisión fiduciaria; $c$ ) el mando del comercio de la plata en los ámbitos interno e internacional, con el objeto de intervenir en el mercado internacional de divisas instituido en el patrón oro-plata, y $d$ ) el monopolio de la emisión de billetes como títulos de pago utilizados comúnmente entre el comercio.

Una segunda característica de esos proyectos fue el intento por adquirir el carácter de "banca de gobierno" o de "Estado", para lo cual el régimen imperial les aseguraría el curso legal de sus billetes al admitirlos a la par en las oficinas de la Hacienda Pública en todo el país, además de concederle la potestad de desempeñarse como intermediarios financieros ante los acreedores internos e internacionales, a cambio de la apertura de una cuenta corriente comercial con base en la cual el banco determinaba el monto en común acuerdo con Maximiliano, respaldada en

\footnotetext{
${ }^{19}$ Los provectos reflejaban igualmente la reanimación de la actividad mercantil del país, y en particular del eje México-Veracruz, según relataban viajeros y contemporáneos. Al lado de la recuperación de los negocios se expresaron otros signos de reanimación, como fueron las innovaciones en la legislación mercantil definidas en el Código de Comercio de 1852, además del impulso que se dio para fomentar la actividad económica, a través de la creación del Ministerio de Fomento, Colonización, Industria y Comercio (1853) destinado a promover la colonización extranjera, la apertura de nuevas fuentes productivas y las obras de comunicaciones y de traza urbana. Véase Ludow, 1995, pp. 351-357.
} 
la hipoteca de diversos ingresos fiscales, pero sujeta a una tasa baja de interés $(6 \%)$ en caso de incumplimiento.

En tercer término, se observa en todos estos proyectos de creación de instituciones de crédito, la promesa de atender los servicios bancarios requeridos por los empresarios de aquellos años, y ofrecerles realizar, entre otras, las funciones propias de una banca de servicios comerciales como el descuento, el cobro de documentos, el manejo de cuentas corrientes y el cambio.

La propuesta para fundar el Banco de México fue promovida por el entonces ministro francés de Hacienda, Archile Fould en octubre de 1863, quien avaló que el Erario francés, fuera del presupuesto aprobado, consiguiera un costoso crédito respaldado con los ingresos aduanales; estos recursos se destinaron, en parte, a cubrir una cantidad al gobierno francés con base en el contrato de Miramar (21 000000$)$ y pagar una indemnización a los acreedores franceses (2.5 000000 de pesos), pero la mayor parte debería ser entregada al mariscal Aquiles Bazaine para que pagara a las tropas francesas, dada la necesidad de formar un "verdadero ejército" que pudiera evitar en el futuro, serios reveses como el sufrido meses antes en la ciudad de Puebla, y que en el corto plazo obligó al presidente Juárez a dejar la ciudad de San Luis Potosí y emigrar hacia el norte del país. Además de Fould, participaron también en ese crédito las firmas francesas de Heine, de Marcuard y Cía., de Hottinguer y Cía., y quedó como responsable de la operación la firma londinense de Glynn \& Mills, que aportó gran parte de los recursos de un préstamo al presupuesto francés que fue calificado como de "muy elevado". ${ }^{20}$

${ }^{20} \mathrm{El}$ ministro de Finanzas, Archil Fould calculó en 3000000 de francos estos gastos, Barbier, 1991, p. 219. Véase también G. Gille, 1965, pp. 205-209. La propuesta fue presentada en septiembre de 1863 a Maximiliano por Francisco de Paula de Arrangoiz, en su calidad de presidente de la comisión de Hacienda de la Asamblea de Notables, y por Bourdillon del Times de Londres en México, que precisó que la alianza financiera franco-británica, sería "[...] un medio indirecto de asegurar la monarquíe mexicaine [...]" (en francés en el original), en Conte, 1944, pp. 611-612. Ver el texto de la Convención de Miramar y los términos del préstamo, en $\mathrm{P}_{\text {AwNo, }} 1980$, pp. 774-779. 
Tanto Fould como Heine y Hottinguer condicionaron el préstamo a Bonaparte a la concesión gubernamental para fundar una institución de crédito que se denominaría Banco de México. ${ }^{21}$

La noticia acerca del establecimiento de este banco se difundió en México hasta el 18 de marzo de 1864 en el periódico La Sociedad. ${ }^{22}$ En la nota se informó que el acuerdo había sido firmado en la ciudad de París, días antes (2 de enero), entre uno de los miembros de la Regencia, el general Juan Almonte y una sociedad de banqueros franceses compuesta por el citado ministro de Hacienda y los financieros Salomón Heine, el representante de la casa de Oppenheim y Cía., y del Crédit Mobilier, firma promovida por las dinastías financiera y política de la familia Pereire, todos ellos firmes apoyos financieros del régimen bonapartista. Además, se afirmó que en el contrato de concesión también se aceptó que la empresa abriera sucursales y agencias en todo el territorio mexicano, en las cuales se podría recibir el pago de los impuestos federales, obligaciones que podían ser cubiertas con los billetes del banco que se aceptarían con curso voluntario en todo el país, con el propósito de animar y facilitar los negocios del comercio a quienes se invitaba, además, a intercambiar pagarés o letras de cambio y metales preciosos. ${ }^{23}$

Un mes más tarde, el periódico notificó al público la decisión de Maximiliano de no aprobar la concesión que el general Almonte había otorgado a los banqueros franceses para fundar la primera institución de crédito del país. La negativa se justificó con base en un juicio de índole liberal contra el otorgamiento de privilegios, dado que una situación de excepción como ésta legitimaba la creación de "un verdadero monopolio oneroso [para el] país". ${ }^{24}$

${ }^{21}$ G. Gilie, 1965, pp. 224-225.

${ }^{22}$ La Sociedad, Periódico político y literario (18 mar. 1864), núm. 274, p. 2.

${ }^{23}$ Bertrand Gille afirma que no se conoce con precisión la participación del grupo del Crédit Mobilier en la fundación de ese banco en México, sin embargo, hay varios administradores del crédito que participaron en el proyecto. B. GiLLe, 1970, pp. 175-176.

${ }^{24}$ La Sociedad, Periódico político y literario (12 abr. 1864), núm. 298, p. 1. 
La negativa de Maximiliano formó parte de la diferencia de opiniones frente al grupo financiero que rodeó a Bonaparte, en particular, la "Comisión Financiera Mexicana" establecida de acuerdo con el Tratado de Miramar, con el objeto de atender los reclamos de los residentes extranjeros, vigilar el manejo del tesoro imperial y convenir los créditos en el extranjero, además de negociar los adeudos pendientes con ingleses y franceses. ${ }^{25}$

A lo anterior se añadían diversas razones de las autoridades que apreciaban que el permiso bancario

[...] era contrario a las ideas liberales, que en economía politica profesa el archiduque. El futuro emperador, que toma por lo serio el régimen constitucional, quiere reservar á los representantes de la nación, la decisión de las cuestiones financieras y económicas; por lo que se enviará anticipadamente al consejo de Estado una petición de concesión, la que después se someterá al voto de la Asamblea nacional. ${ }^{26}$

Los contemporáneos afirman que esta negativa provocó el reclamo del ministro de Hacienda francés, Archil Fould al mariscal Aquiles Bazaine, cabeza de las tropas imperiales en México, porque se desperdiciaba una gran oportunidad dado que "la banca es el instrumento más útil para el desarrollo del crédito en México". ${ }^{27}$

Al poco tiempo del arribo de Maximiliano a la ciudad de México se hizo patente la imposible reconstrucción de la

${ }^{25}$ La Comisión Financiera Mexicana fue dirigida por el Conde de Germiny, que era gobernador honorario del Banco de Francia y había sido ministro de Hacienda y el financiero Corta, supervisor de la Hacienda Pública mexicana, en Lefểre, 1869, pp. 144-145. Véase también PAYNo, 1980, pp. 765-770 y 779-786.

${ }^{26}$ La Sociedad, Periódico politico y literario (12 abr. 1864), núm. 298, p. 1.

${ }^{27}$ Rrvera Cambas, 1987, vol. n, pp. 636 y 637. Según el entonces presidente de la Comisión de Hacienda en París, Francisco de Paula de Arrangoiz, Maximiliano expresó en un carta escrita en Bruselas acerca de sus dudas de ir a París "[...] por temor de que M. Fould volviera a la carga para arrancarle la sanción del decreto expedido por el general Almonte rela tivo al Banco [...] ", a lo que agrega que esto fue motivo de desconfianza entre la administración bonapartista y el futuro emperador, en ARRANcorz, 1968, p. 574. Las cursivas son del autor. 
estructura financiera mexicana, tarea que se habían propuesto llevar a cabo consejeros del emperador, financieros y banqueros afines a esta aventura, así como los funcionarios franceses enviados a México. La diferencia de puntos de vista entre unos y otros se acentuó a medida que los conflictos hacendísticos del régimen imperial se agravaron. Reclamos que se sumaron a los acreedores ingleses ${ }^{28}$ que debieron sacrificar sus ingresos aduanales como resultado de medidas de reordenación administrativa que impuso, por una parte, la administración liberal, pero también el mando militar encabezado por el mariscal Bazaine, no obstante que los recursos del tesoro eran insuficientes para sufragar los gastos de la corte y satisfacer los compromisos que el emperador establecía con los grupos y sectores que le apoyaban. ${ }^{29}$

El 19 de noviembre de 1863 fue presentado el segundo plan para fundar el Banco Imperial Mexicano, proyecto que fue presentado por un consorcio anglo-francés denominando Société Internationale et Financière dirigido por el banquero anglo-holandés Hope y la firma inglesa de Glynn Mills y Cía., en Londres. Esta última había convenido con los banqueros franceses tomar el saldo no cubierto por el primer préstamo (61000 000 de pesos).$^{30}$

La Société Financière Internationale o International Financial Society formó parte de los sindicatos bancarios o "bancas de negocio" que se fundaron indistintamente en Londres y París, con el objeto de combinar intereses y recursos de banqueros, comerciantes y financieros dedicados especialmente a la promoción de las "bancas coloniales", también llamadas "overseas bank". Esta firma nació en mayo de 1863 por la combinación del Crédit Mobilier de los Pereire, y posteriormente de la casa parisina de Mallet

${ }^{28}$ G. Gil.LE, 1965, pp. 200-224 y BdzaNT, 1981, pp. 101-106.

${ }^{29}$ Fuente importante para reconocer las clientelas del imperio de Maximiliano es sin duda el texto de Paxo, 1982.

${ }^{30}$ G. Gille, 1965, pp. 209-211. Los agentes más destacados de estas firmas fueron la casa de Manning y Mackintosh para el caso de la firma Baring, y agentes como Drusina, y posteriormente Davidson para la banca Rothschild. Sobre los términos del convenio, Paino, 1980, p. 771. 
y Cía., con las firmas inglesas promotoras de la Banca Otomana y de otras instituciones en Austria y Egipto, posteriormente. ${ }^{31}$

Partícipe de la aventura europea en México la Société Financière Internationale ${ }^{32}$ recuperó las directrices y parte de los compromisos de la primera iniciativa. Uno de los miembros del consorcio, la casa inglesa de Glynn Mills \& Co., intentó negociar con el Crédit Mobilier, pagar el saldo no cubierto por las firmas francesas en el préstamo citado con anterioridad, ${ }^{33}$ pero al no tener éxito por las dificiles condiciones que impuso el Crédit, éste tras varios meses de negociaciones traspasó el compromiso a Baring \& Brothers, agente financiero de México en Londres. ${ }^{34}$

En tanto esto ocurría, la Société Internationale Financière decidió someter a las autoridades imperiales su autorización para fundar el Banco Imperial Mexicano. El Archivo General de la Nación guarda un borrador manuscrito de este proyecto, en el que se definen las características de esta institución, a la que se le califica, en primer término, como "Banco del Estado" (con base en el modelo del Banco de Francia) dado que su funcionamiento debía quedar "[...] bajo la protección de su Majestad [...] y la vigilancia de su Gobierno [...]" que estaría representada por un comisario y un inspector, al lado de quienes estaría el Con-

${ }^{31}$ La compañía contó con un capital nominal de 3000000 de libras y sus 150000 acciones fueron suscritas en París y Londres, pero el dominio inglés fue razón del retiro del Crédit Mo'silier y sus filiales en Italia, España y Holanda, en Cottres, 1973, pp. 181-182. Los términos de la operación en Payno, 1980, pp. 782-786.

${ }^{32}$ Carta de Hope al Conde Fery Zichy, fechada en Trieste, 8 de abril de 1864, 8 ff. AGN, II Imperio, vol. 10, exp. 47, "Bancos nacionales", 1864.

${ }^{33}$ Sobre ello, comenta Arrangoiz que en esta operación no participó ningún mexicano, y que Zichy logró la operación, gracias a la confianza que le tenía Maximiliano, véase también el texto del préstamo firmado por Maximiliano y Bonaparte en Tul.terías, 1968, pp. 575 y 580-581. Conte afirma que los ingleses aceptaron dar el empréstito porque parte de estos recursos fueron entregados a los acreedores británicos, Conte, 1944, pp. 241 y 619.

${ }^{34}$ Cottrei., 1973, pp. 183-184. La negociación entre firmas francesas e inglesas en G. GII.LE, 1965, pp. 211-213. 
sejo de Administración formado por un director-gerente y tres miembros que serían nombrados por los socios fundadores en París y Londres durante los cinco primeros años, posteriormente, se planteó que fueran denominados o elegidos por la asamblea de accionistas. Además, se estableció en el proyecto que la futura institución estaría capacitada para realizar todo tipo de operaciones de crédito al gobierno y entre los particulares, además de tener en monopolio la emisión para billetes que serían reconocidos al portador y tendrían curso legal. Entendiendo por ello que fueran recibidos en las oficinas de la Tesorería y ser canjeados a la par, tanto los billetes emitidos por la matriz como los de sucursales.

Por último, la firma se comprometía a abrir una cuenta al gobierno imperial en México por 10000000 de francos (equivalentes a 50000000 de pesos) con respaldo de los recursos provenientes de la aduana y de otras contribuciones fiscales, mientras que el gobierno se responsabilizaba a ceder el terreno necesario para la construcción del edificio de la matriz siempre que la firma la costeara, pero una vez que caducara la concesión el gobierno devolvería a los inversionistas el mon to gastado para esta obra, además de solicitar la autorización para que el banco quedara libre de todo tipo de impuestos. ${ }^{35}$

El periódico La Sociedad dio a conocer al público mexicano, el 12 de abril de 1864, la noticia de estas negociaciones, información que había sido tomada del Diario de la Marina publicado en la ciudad de La Habana, Cuba, al señalar que "los especuladores ingleses" habían reunido 50000000 de francos (equivalentes a 250000000 de pesos) con el objeto de fundar un banco en la ciudad de México, pero — se añadía- que aún no se había recibido la autorización requerida. ${ }^{36}$

35 (Borrador del) Proyecto Banco Imperial Mexicano (19 nov. 1863), 16 ff., en AGN, II Imperio, vol. 10, exp. 47, "Bancos nacionales", 1864.

${ }^{36}$ La Sociedad, Periódico político y literario ( $1^{\circ}$ mayo 1864), núm. 317 , p. 2. 
Desconozco la razones que motivaron que este banco no fuera instalado, pero es posible que ello hubiera sido resultado de la imprevista apertura de una filial inglesa denominada Banco de Londres, México y Sudamérica que desalentaría la iniciativa sin que aquél tuviera necesidad de obtener autorización de los imperios mexicano y francés, además de haber sido promovido por la casa bancaria de Baring \& Brothers, que en los primeros meses de 1864 entraba en las operaciones financieras europeas con el imperio de Maximiliano por acuerdo de Pereire, que era uno de los banqueros más cercanos a Bonaparte y al ministro de Finanzas Archile Fould.

En septiembre de 1864, el rechazo de Maximiliano al primer proyecto bancario aprobado por la Regencia y la sorpresiva entrada de una filial bancaria inglesa en la ciudad de México, motivó la definición de un nuevo préstamo y de un tercer proyecto bancario. ${ }^{3 \dagger}$ Los financieros franceses presionaron a Maximiliano mediante la intervención de Bonaparte con el fin de "frenar el descrédito del préstamo de Miramar"38 y cumplir con los firmantes de la convención francesa que habían recibido mínimas cantidades, lo que suponía acercarse con la casa francesa de Rothschild que había otorgado dos préstamos a los gobiernos de Miramón y Márquez, además de su participación en la firma de Jecker y Cía., ${ }^{39}$ acreedora del tesorero mexicano y promotora de la empresa francesa, de acuerdo con la historiografia.

Bonaparte reintrodujo en la negociación la primera propuesta bancaria con los promotores. Por su parte, Maximiliano estaba en favor de la negociación ante la urgencia de solventar sus gastos administrativos y de la corte, para

${ }^{37}$ Según Conte esta iniciativa provino de una entrevista en la ciudad de Compiègne entre el rey Leopoldo de Bélgica y el emperador Bonaparte con Archile Fould, antiguo presidente de la Banca de Francia y el financiero Corta al terminar su residencia en México, Conte, 1944, p. 302. La negociación de esta operación en G. GLre, 1965, pp. 211-224. Véase Lefêbre, 1869, pp. 153-154.

${ }^{38}$ Las negociaciones sobre el crédito comenzaron en junio de 1864 , véase $P_{\text {Ano }}, 1980$, pp. $772-774$ y 788-792.

39 G. GilLe, 1965, pp. 195-197. 
lo cual participaron como responsables del emperador francés, Eloin, responsable de la Casa Imperial y el diputado Corta, anterior responsable de la Hacienda Pública en México, y por parte del ex príncipe austríaco Bourdillon corresponsal del Times de Londres en México y el legislador inglés o comerciante inglés en México, Barron, heredero del antiguo cónsul inglés en México, fundador de una próspera casa mercantil y bancaria en la ciudad de San Francisco, inserta en el auge del oro californiano. ${ }^{40}$

La primera comisión optó por traspasar la responsabilidad al antiguo grupo de financieros compuesto por connotados miembros de la llamada "Haute Banque" o "banca protestante" que fuera fortalecida durante el periodo de Luis Felipe d'Orleáns, entre las cuales se encontraban las casas bancarias francesas de Hottinguer y Cía., ${ }^{41}$ Mallet y Cía., Seilliere y Cía., Marcuard y Cía., A.M. Heine junto a las firmas inglesas de Finlay y Cía., Hodgson y Cía., y Pillet Will y Cía., las dos primeras casas bancarias londinenses fundaron con el Crédit Mobilier la Compagnie Financière International de Londres. ${ }^{42}$

Los responsables de la operación definieron los montos, condiciones de un crédito que debía compartirse entre el Tesoro francés y el erario imperial mexicano, ${ }^{43}$ a la vez que redactaban el reglamento del futuro Banco Nacional Franco Mexicano cuya concesión gubernamental debía aprobar su funciones como institución de emisión y descuento, partícipe en ella compra venta de metales preciosos y responsable de las cuentas gubernamentales. Dirigida por un comité de cinco miembros en París y otro en México, el

\footnotetext{
${ }^{40}$ Sobre este punto es importante aclarar que en algunos de los textos se menciona a Barron y en otros a Baron.

${ }^{41}$ A lo largo del siglo la firma de Hottinguer participó en la compra venta de plata en el mercado internacional, así como en diversas actividades bancarias y financieras, en Bonin, 1991, pp. 15-17.

${ }^{42}$ Como representante de la futura sociedad en México fue nombrado Miguel Heine. Véase Arrangorz, 1968, pp. 625 y 626 . El texto de la carta de Maximiliano a Napoleón III, en Conte, 1944, pp. 637-638 y G. Gille, 1965, pp. 226-229.

${ }^{43}$ G. Gille, 1965, pp. 211-224 y Arrangoiz, 1968, pp. 625-626. Véase también Rivera Cambas, 1987, vol. mi, p. 65.
} 
cual sería nombrado por la Asamblea General que se reuniría anualmente.

El préstamo se entregó sólo en parte a pesar de lo anunciado en París sólo hubo dos pequeñas emisiones, pero el banco no fue fundado. ${ }^{44}$ La iniciativa no tuvo éxito a causa de la diferencia de opiniones que se sucedieron entre los representantes de Maximiliano y los miembros de la Comisión Financiera Mexicana que radicaba en París, entre los gobiernos imperiales acerca del manejo de la Hacienda Pública mexicana, diferencia que se sumó y confundió con las dificultades acumuladas a lo largo de seis meses para lograr un acuerdo entre los financieros parisinos y londinenses con los representantes de Bonaparte y los funcionarios del imperio de Maximiliano.

A fines de 1864, tras el fracaso de los proyectos anteriores y dada la inclusión de la banca Rothschild en las últimas negociaciones de crédito, Nathaniel Davidson, agente de las ramas inglesa y francesa y miembro de la Comisión de Hacienda del Imperio mexicano, a su regreso a México presentó la cuarta propuesta bancaria, con el fin de establecer el Banco Nacional, proyecto que se difundió en un folleto en el que se definían los rasgos y atribuciones de la futura institución.

En el texto solicitó el establecimiento de esta firma sobre iguales bases y funciones definidas en los tres proyectos anteriores. Con la gran diferencia de que Davidson pensaba para este futuro banco que se lograra conjuntar intereses y los recursos de capitalistas mexicanos y extranjeros, que a suijuicio permitiría al gobierno lograr simultáneamen te créditos externos y préstamos de los mexicanos. Esto tenía el objeto de lograr "conciliar" estos intereses "hasta llegar a identificarlos al grado de no ser posible su distinción”.

Una segunda diferencia entre esta iniciativa y las anteriores fue el hecho de que el proyecto no fue antecedido de

${ }^{44}$ Lefêbre señala que hubo una gran especulación sobre esta operación promovida fundamentalmente por los miembros de la Comisión Fin anciera radicada en París, LefîBrf, 1869, pp. 154-155. Se trata de los llamados "azulitos" o "petits bleus" que quedaron sin pagar hasta el periodo de Díaz, su historia en Topk, 1993, pp. 445-470. 
ningún préstamo internacional, que en este caso debió haberse promovido por alguna de las ramas de los Rothschild, que esperaban los resultados de los sucesos europeos que cambiaron el equilibrio de fuerzas en el viejo continente, producto de cambios azarosos como fueron los fallecimientos de lord Palmerston, primer ministro inglés y del rey Leopoldo de Bélgica, quienes habían sido importantes aliados de Napoleón II en la aventura imperial mexicana.

Dado a la crisis en el escenario internacional y ante la creciente debilidad de Maximiliano por las diferencias con el Vaticano, y por ende con los conservadores, Nathaniel Davidson esperó también los resultados, con el fin de evitar un nuevo error como el de septiembre de 1858 en que concedió un préstamo al gobierno de Miramón a cambio de propiedades eclesiásticas, operación que hubo de revisar en 1861 con las fuerzas juaristas, que le condicionaron el reconocimiento de las operaciones anteriores a cambio de dinero en efectivo. ${ }^{45}$

Davidson, al igual que otros agentes de la banca inglesa, era buen conocedor del mundo de los negocios de la ciudad de México y estaba al tanto de la debilidad financiera de la administración imperial por formar parte de la Comisión de Hacienda en París por lo que realizó operaciones diversas que le fueron solicitadas por el gobierno imperial de Maximiliano. ${ }^{46}$ Pero no promovió el otorgamiento de ningún nuevo crédito dada la situación incierta en que se vivía. Por ello, buscando alejarse de los vaivenes de la política, Davidson en colaboración con Pío Bermejillo, Juan Antonio Béistegui, Eustaquio Barron y Manuel Escandón, ${ }^{47}$ directivos de importantes casas bancarias mexicanas promovieron, a fines de 1864, la fundación de un establecimiento bancario que debiera contar con el concurso de los viejos y nuevos miembros de la "élite del dinero".

${ }^{45}$ El llamado "Negocio Davidson", en Payso, 1982, pp. 117-130.

${ }^{46}$ Entre 1865-1866 se le entregaron por premio 5500 pesos, además de las cantidades remitidas a Europa por la emperatriz Carlota, y de la entrega de cantidades autorizadas por la Comisión, en PAwo, 1980, pp. $663,674,676$ y 686 .

${ }^{47}$ Banco de Londres y México, 1864, p. 20. 
Todos ellos acreedores internos del imperio durante los últimos años de la vida de este régimen, que respaldaron sus créditos con ingresos aduanales o que se vieron obligados a otorgar una contribución cotidiana a la administración central del imperio. ${ }^{48}$ Ataduras que se traducirían en oposición a Maximiliano, razón por la cual algunos de estos propietarios y capitalistas optaron por establecer vínculos con las fuerzas liberales, cuyos ejércitos avanzaban sobre la capital y a los cuales facilitaron pertrecho y alimentos, $\mathrm{CO}^{-}$ mo fue el caso de Limantour padre, de Carlos Haghenbeck, de Ricardo Saínz, de Luis Sauto o de Íñigo Noriega.

Entre los miembros de esa "élite del dinero" se encuentran algunos personajes que participaron en la creación de instituciones de crédito del periodo porfirista, ${ }^{49}$ otros, en cambio, desaparecieron de la primera línea del mundo de los negocios de la ciudad de México, como fue el caso de varios herederos de la "aristocracia del dinero" como Manuel Agreda, la testamentaria de Alamán o los hermanos Torres Adalid o la familia de Lizardi, así como prestigiados empresarios mexicanos de mediados de siglo como Gregorio Mier y Terán, Cayetano Rubio o Martín Carrera. En tanto que otros acreedores imperiales preservaron su sitio en este universo, entre quienes destacan fortunas familiares de origen colonial o del periodo independiente como fueron las familias de los Iturbe, los Escandón, los Béistegui o los Landa entre otros, que permanecieron al lado de prósperas firmas de comerciantes españoles como la de los hermanos Muriel, de Cardeña y Cía., de Francisco de P. Portilla o de Pío Bermejillo, de ingleses como Barron y Forbes o de Graham Greaves, o de franceses como las firmas de Labadie, de Bablot o de Zolly, así como capitales de residentes prusianos o hanseáticos como el cónsul Benecke o la casa de Uhink, entre otras muchas que desa-

\footnotetext{
${ }^{48}$ Estos inversionistas facilitaron recursos a todas las administraciones o fueron víctimas de préstamos forzosos o de toma forzada de bienes, la lista de estos personajes o firmas de vieja filiación o recién llegados, se encuentra en PAYNO, 1980, pp. 876-898.

${ }^{49}$ Ludlow, 1990 , pp. 979-1028.
} 
rrollaron sólidas redes mercantil y financiera entre la ciudad de México y diversas plazas del país.

Davidson invitó a esos capitalistas que dominaron el mundo de los negocios de la ciudad de México, durante los primeros años del régimen porfirista, al proponerles fundar una institución emisora con carácter exclusivo y monopólico, que hiciera frente a la filial inglesa. Por lo cual planteaba, por primera vez en la historia monetaria mexicana, el reconocimiento del "curso legal" de esos billetes bancarios, cuya introducción debe ser paulatina en el entendido que los metales preciosos seguirán siendo la base del sistema monetario, pero aconsejaba que no se debía entorpecer su exportación. En uno de sus párrafos, el agente de Rothschild consideró que "hubiera desaparecido la nacionalidad mexicana, a no ser por el equilibrio que se ha mantenido entre los metales preciosos por medio de la exportación constante de las platas producidas por nuestras minas". Más adelante precisaba las cantidades que debían aportar los futuros accionistas, con el fin de que participasen "capitalistas y comerciantes de esta capital" con 5000000 de pesos hasta completarse la suscripción de 20000000 que debía ser el total del capital social restante que debía ofrecerse en las plazas europeas; insistía, por último, acerca de la importancia de que participasen los inversionistas mexicanos, ya que con ello evitarían ser excluidos de negocios y giros de primera importancia. ${ }^{50}$

Pero la quiebra del imperio en términos políticos y financieros limitó los avances, y la iniciativa no fue retomada, sino hasta 1882 al ser restablecidas las relaciones diplomáticas y financieras con los gobiernos de Francia e Inglaterra. ${ }^{51}$

Unos meses antes, hacia fines de 1863, un grupo de capitalistas londinenses promovió el establecimiento de una

50 Davidson, 1864.

${ }^{51}$ Ludow, 1986, pp. 299-345. 
filial de una banca colonial a la qué inicialmente llamaron Bank of México Limited, y firmaron su acta constitutiva el 15 de febrero de 1864, en el entendido que esta casa formaba parte de futuros establecimientos en Argentina, Brasil, Perú y Chile.

Los banqueros ingleses tuvieron que cambiar el nombre de la futura institución bancaria, al hacerse públicas las negociaciones que el Comité Financiero Mexicano entablaba con los representantes de la Regencia para fundar un banco con el mismo nombre (Banco de México), a la vez que otorgaban el crédito de Miramar para sufragar el gasto de traslado de los ejércitos del mariscal Bazaine.

La debilidad financiera del régimen de Maximiliano ante la élite económica parisina fue aprovechada por los capitales ingleses conocedores de la situación mexicana, como era el caso de agentes y comisionistas ligados a la casas bancarias londinenses de los Baring, que controlaba gran parte del comercio de metales, en particular, en monedas de plata que eran remitidas a diversos países de Europa, a Estados Unidos y a China. Las filiales de la banca inglesa en México y Latinoamérica, ${ }^{52} \mathrm{o}$ en otras ciudades como El Cairo, Shanghai y Hong Kong, fueron promovidas por un poderoso sindicato formado por sociedades como los "Joint stock bankers" o las pujantes compañías de seguros, así como individuos miembros de las minorías política y económica londinenses como era el caso de los "merchant bankers" así como de varias firmas que dominaron el comercio de plata mexicana y la deuda interna, como fue el caso de la firma de Baring y hermanos. En su mayoría estaban vinculados con el tráfico de diversos productos de exportación como fueron la plata, el algodón, el café o el cobre, entre otros, y que promovian la formación de estas asociaciones de accionistas con el fin de hacer frente a la competencia de otras firmas europeas.

${ }^{52}$ Bajo esta denominación e iguales características se fundaron diversas firmas en varias regiones del mundo, entre las que se encontraba el Banco de Londres y Río de la Plata, administrado por la casa bancaria inglesa de los Baring, en CAssis, 1987, p. 38. 
Eso les permitió escapar de la disputa financiera que establecieron los medios de aportación franceses e ingleses y sin buscar concesión gubernamental ni privilegio alguno optaron por establecer el primer banco del país, para lo cual enviaron a la ciudad de México a los representantes Guillermo Newbold y Roberto Geddes que llegaron al puerto de Veracruz el $1^{\circ}$ de mayo de $1864 .{ }^{53}$

Durante su primer año de vida, los directivos de la filial mexicana tras de matricularse en el Tribunal de Comercio de la ciudad de México optaron por expandir sus actividades y relaciones con el comercio y las firmas bancarias existentes, beneficiándose de la incierta situación de las ofertas bancarias presentadas a las autoridades mexicanas y francesas. ${ }^{54}$

Una vez llevados a cabo los registros y arreglos necesarios para la apertura de la casa matriz, el de Londres, México y Sudamérica se anunció en la prensa como una empresa emisora con un capital de 2000000 de libras esterlinas, o sean 10000000 de pesos, y se aclaró que se tenía la "facultad de aumentarlo". Y se precisaba, además, que la primera emisión ya había terminado, y alcanzó la cifra de 1000000 de libras equivalente a 5000000 de pesos; cantidad que fue suscrita en 20000 acciones con un costo de 50 libras (250 pesos). Y se consideró que el monto del capital reunido era una "circunstancia que desde luego proporciona mayores garantías de las que pudieren ofrecer las empresas particulares", además, se aseguraba que serían otorgados los mismos beneficios que se daban en Inglaterra a las instituciones por acciones conocidas como los "Joint Stocks Banks" (banca por acciones). ${ }^{55}$

${ }^{53}$ La Sociedad, Periódico político y literario (3 mayo 1864), núm. 319, p. 3. La narración de la llegada de estos agentes en el cap. i del libro de aniversario del Banco de Londres y México, 1964.

${ }^{54}$ Antes del registro del Banco Newbold obtuvo su matricula núm. 4327 expedida el 6 de mayo, en AGN, Ignacio Cosio, vol., 371, ff. 251v.254v. y 256. Días más tarde, el 22 de junio obtuvo la matrícula requerida, de acuerdo con el 53 del Código de Comercio de 1854, y reportó el establecimiento del primer local en la calle de Capuchinas núm. 3 (hoy Venustiano Carranza).

${ }^{55}$ La Sociedad, Periódico político y literario (5 jul. 1864), núm. 380, p. 2. 
Por último, Newbold y Geddes difundieron, en la prensa y mediante diversas cartas, los rasgos y objetivos de la futura institución que contaba con un capital social de 10000000 de pesos, y anunció que realizaría todo tipo de operaciones mercantiles y bancarias como:

1. El descuento de letras de cambio, tanto del comercio como de otras procedencias que merezcan la aprobación del Banco.

2. Hacer préstamos de dinero con garantía de propiedades o productos que el Banco estime satisfactorios, con el interés y por el tiempo que mutuamente se acuerde.

3. Admitirá también el Banco, depósitos de dinero por el tiempo y con el interés que de común acuerdo se arreglare al efectuar tales depósitos.

4. El Banco abrirá cuentas corrientes sin cargo alguno para el uso y conveniencia de su clientela.

5. El Banco descuenta las libranzas del comercio y negocia letras de cambio sobre Londres, París y otras ciudades principales de Europa y América, y también sobre las ciudades del Interior donde tiene agencias, al cambio corriente en las fechas en que se verifiquen tales operaciones.

En aquellos textos dirigidos a sus potenciales clientes, los representantes ingleses aprovechaban la ocasión para difundir el papel de las instituciones de crédito en los siguientes términos

Las ventajas que establecimientos de esta clase proporcionan al comercio y al público, son bien sabidas. El numerario en circulación aumenta con ellos, y los agricultores, comerciantes y empresarios de todo género, obtienen fondos a interés moderado.

La noticia que damos, constituye una nueva prueba de la confianza que los capitalistas europeos, que tan renuentes se habían manifestado siempre, van teniendo en cuenta la estabilidad de nuestras nuevas instituciones. ${ }^{56}$

La administración de Newbold se mostró conocedora de las prácticas mercantiles mexicanas y de inmediato se rela-

${ }^{56}$ La Sociedad, Periódico político y literario (10 mayo 1864), núm. 326, p. 3. 
cionó con numerosas casas del país en los primeros meses de vida del Banco, gracias a lo cual se logró establecer una red amplia de negocios con las firmas locales y la institución pudo con ello concentrar esas operaciones bajo su égi$\mathrm{da}$, pero ofreciendo por igual los servicios bancarios a empresas grandes y pequeñas dedicadas a actividades diversas, seguramente todas ellas vinculadas desde hacía años con las casas bancarias y mercantiles inglesas.

\begin{tabular}{|c|c|c|}
\hline Ciudad & Fima & Actividad \\
\hline Acapulco & $\begin{array}{l}\text { Raimundo Fernando y Sobrinos } \\
\text { Pedro Narvarte y Cía. }\end{array}$ & \\
\hline Aguascalientes & Gómez de Hornedo y Hnos. & \\
\hline Celaya & Tomás Horncastle & \\
\hline Campeche & Domingo Trueba & \\
\hline Culiacán & Valentín Vidaurreta & \\
\hline Colima & Oetling y Cía. & Comisión, importación \\
\hline Durango & Antonio Arana & Ropa, algodón, azúcar, etc. \\
\hline \multirow[t]{3}{*}{ Guadalajara } & Francisco Martínez y Cía. & Almacén y banco \\
\hline & Fernández Somellera y Hnos. & Comerciante \\
\hline & Domingo Llamas & Almacén y banco \\
\hline \multirow[t]{3}{*}{ Guanajuato } & T. Lehman & \\
\hline & Luis McGowan & Comerciante \\
\hline & Demetrio Montes de Oca & Comerciante \\
\hline Guaymas & $\begin{array}{l}\text { J.A. Robinson } \\
\text { Francisco Espriû }\end{array}$ & \\
\hline Hermosillo & Celedonio Ortiz & \\
\hline Matamoros & $\begin{array}{l}\text { José Sanromán } \\
\text { Albino López } \\
\text { Francisco Armendáriz } \\
\text { Hernández y Hnos. } \\
\text { Bahnsen y Cía. }\end{array}$ & \\
\hline Mérida & Bernabé de Mendiolea & \\
\hline Morelia & $\begin{array}{l}\text { Nicolás de Oruña } \\
\text { Manuel Elguero }\end{array}$ & $\begin{array}{l}\text { Almacén } \\
\text { Tabaquería }\end{array}$ \\
\hline Monterrey & $\begin{array}{l}\text { Nazarena, Cortes y Cía. } \\
\text { Echeguren, Quintana y Cía. }\end{array}$ & \\
\hline Puebla & $\begin{array}{l}\text { Velasco Hnos. } \\
\text { Nerón y Cía. }\end{array}$ & $\begin{array}{l}\text { Escritorio } \\
\text { Almacén y companía }\end{array}$ \\
\hline Puerto Isabel & Castaño Hermanos & \\
\hline San Luis Potosí & Davies y Cía. & Almacén \\
\hline Tepic & Nazarena Cortés y Cía. & \\
\hline Tabasco & $\begin{array}{l}\text { Nicolás Rondamina } \\
\text { Juan Ruiz }\end{array}$ & \\
\hline
\end{tabular}




\begin{tabular}{|c|c|c|}
\hline Ciudad & Firma & Actividad \\
\hline \multirow[t]{12}{*}{ Tampico } & Diego de Lastra & Importación de ropa \\
\hline & Dionisio Camacho & Almacén, comisión \\
\hline & & Agente Cía. Transatlántica Francesa \\
\hline & & West Indian \& Pacific Co. \\
\hline & & Representante de seguros París-Marsella \\
\hline & Manuel A. Fernández & Pulpería, abarrotes \\
\hline & A. Gutiérrez y Victory & Almacén, comisión \\
\hline & Ramón Obregón & Importación, ropa \\
\hline & Víctor García y Stewart & Almacén, comisión \\
\hline & Jolly y Cía. & Almacén, comisión \\
\hline & & Agente de los vapores Royal mail \\
\hline & & Steam Packet y del Lloyd de Londres \\
\hline \multirow[t]{6}{*}{ Veracruz } & $\begin{array}{l}\text { Velasco Hnos. } \\
\text { Labadie y Cía. }\end{array}$ & \\
\hline & $\begin{array}{l}\text { Francisco Cano o Canal } \\
\text { José Beltrán Salazar }\end{array}$ & Corredor \\
\hline & Andrés Anglade y Cía. & Agente vapores españoles \\
\hline & $\begin{array}{l}\text { A. Somohano y Cía. } \\
\text { Graham Greaves y Cía. }\end{array}$ & Almacén \\
\hline & R. C. Ritter y Cía. & $\begin{array}{l}\text { Almacén y representante vapores } \\
\text { EUA; cristalería y locería }\end{array}$ \\
\hline & Viya Hnos. & Almacén \\
\hline \multirow{4}{*}{$\begin{array}{l}\text { Zamora } \\
\text { Zacatecas }\end{array}$} & Jesús M. Plancarte y Cía. & Abarrotes \\
\hline & John V. Clemente & \\
\hline & $\begin{array}{l}\text { Tomás Horncastle y Cía. } \\
\text { Alexander y Cía. }\end{array}$ & Almacén \\
\hline & William Newal y Cía. & \\
\hline
\end{tabular}

Fuentes: AGN, Ignacio Cosío, vol. 371, 1864 y Maillefert, 1992. Parte de esta lista fue publicada en Banco de Londres y México, 1964, pp. 19-20.

La apertura de esta red de operaciones fue respaldada unos meses más tarde con la inauguración de las primeras diez sucursales en los centros mineros y puertos más importantes del país, o en plazas mercantiles de fuerte activi$\operatorname{dad},{ }^{57}$ como fueron:

\begin{tabular}{ll}
\hline Sede de la sucursal & Responsable \\
\hline Veracruz & Batesm Barton y Cía. \\
Tampico & Stewart, Jolly y Cía.
\end{tabular}

${ }^{57}$ Banco de Londres y México, 1964, p. 20. 


\begin{tabular}{ll}
\hline Sede de la sucursal & Responsable \\
\hline Guanajuato & Archibaldo McGowan \\
Zacatecas & Alexander y Cía. \\
& William Newal y Cía. \\
San Luis Potosí & Davis y Cía. \\
Morelia & Manuel Elguero \\
Matamoros & Bahnsen y Cía. \\
Puebla & Nerón y Cía. \\
Colima & Oetling y Cía. \\
Durango & Antonio Arana \\
& Delius Hermanos \\
\hline
\end{tabular}

Además de la red interna y de las representaciones en Londres y París, los directivos de la firma establecieron agencias de la filial mexicana en las capitales de Cuba y Columbia Británica. ${ }^{58}$

Ante la oferta de Davidson y los banqueros mexicanos de abrir un establecimiento bancario, Newbold opinó:

No creo que un nuevo banco aquí nos perjudique, antes era ventajoso, a menos de que se le otorgue el privilegio exclusivo de emitir billetes, que es lo que sus organizadores desean. En mi opinión resultará muy perjudicial imponer una emisión de billetes en este país, que estimo acaba de librarse de una bancarrota completa durante sus revoluciones por la ausencia de papel moneda. Es indudable que una pequeña emisión de billetes sería útil en México; pero ella debe ser limitada y ningún banco disfrutar del privilegio exclusivo de realizarla. ${ }^{59}$

Un año más tarde, al desaparecer en 1865 la amenaza de los potenciales competidores bancarios, Newbold y Geddes optaron por confirmar la existencia del establecimiento, al solicitar su registro ante notario público. ${ }^{60}$ Años más tarde al presentarse la polémica bancaria más importante del periodo porfirista se puso en tela de juicio la validez legal del

${ }^{58}$ La Sociedad, Periódico político y literario (10 mayo 1864), núm. 326, p. 3.

${ }^{59}$ Citado en Banco de Londres y México, 1864, pp. 20-21.

${ }^{60}$ AGNM, Ignacio Cosio, Notario núm. 57, vol. 372, año de 1865, Protocolización de la copia de los Estatutos del Banco de Londres, México y Sudamérica, 2 de marzo de 1865, ff. 136-198. 
Banco de Londres, México y Sudamérica, alegándose que no contaba con la legalidad suficiente. Sin embargo, un especialista de aquellos años nombrado por Manuel Dublán, entonces secretario de Hacienda, afirmó que todos los registros administrativos y notariales eran suficientes para que el banco tuviera vida legal, pues agrega que eran " $[\ldots]$ todos los requisitos exigidos por las leyes entonces en vigor" ${ }^{61}$ Además de que la administración juarista revalidó esta determinación judicial por la Ley del 20 de agosto de $1867 .^{62}$

En el segundo documento otorgado por el notario Ignacio Cosío fue registrada el acta original en la que se senala que el objetivo de la institución de crédito en México era la de promover las relaciones con ese país, razón por la cual se daban plenos poderes a Guillermo Newbold para que pudiera conducir los

[...] negocios de un Banco de depósitos y emisiones, y negocios de Banca en todos sus ramos, descuentos, transacciones de Cambios, especies, fianzas y otros valores y sus representantes, recibir depósitos, de dinero, recibir y hacer empréstitos, emplear fondos, tomar fianzas y disponer de ellas ya sean efectos o garantías personales, servir de Agentes en asuntos monetarios para cualquier Gobierno ó demás autoridades y corporaciones Públicas ó Particulares e individuos, establecer y conducir Ban$\cos$, Bancos Sucursales y agencias en donde la Compañía tuviere por conveniente; y con ese fin aceptar u obtener, poseer $y$ observar los decretos, concesiones, poderes, derechos ú otros privilegios hechos ó que se hagan, concedidos por y cualquier Gobierno ó Autoridad, concernientes a los objetos de la Compañía y emprender, todo y cualquier negocio ú operación financiera y monetaria; y practicar toda y cualquiera cosa que la Compañía de tiempo en tiempo juzgare ser accidental ó sirva para obtener cualquiera de estos objetos o que de alguna manera resulten en beneficio de la Compañía, así como tales adiciones o extensiones que la Compañía de tiempo en tiempo determine y resolviere por resolución especial. ${ }^{63}$

${ }^{61}$ LABastida, 1989, p. 63.

62 Citado en Banco de Londres y México, 1864, p. 33.

${ }^{63}$ En la traducción del poder se indica: El Banco de Londres, México y Sudamérica Limited hace saber: "desea así mismo autorizar a William Newbold $[\ldots .$.$] y como Director del dicho proyectado Establecimiento$ 
El documento fue firmado por los promotores del Banco de Londres, México y Sudamérica:

\begin{tabular}{lcll}
\hline Nombre & Acciones & Domicilio & Ocupación \\
\hline William Julius Marshal & 100 & Londres & Comerciante \\
John Paterson & 100 & Londres & Comerciante \\
James Levy Hart & 100 & Londres & Comerciante \\
Frederick Harrison & 100 & Londres & Banquero \\
London and Country Bank & 100 & Londres & Banquero \\
Charles Argles & 100 & Londres & Caballero \\
William Flux & 100 & Londres & Caballero \\
Edward Hitchings & 5 & Lexington & Caballero \\
\hline
\end{tabular}

De acuerdo con el citado documento el establecimiento sería dirigido desde Londres (16 King William Street) por un comité directivo, en el que participaron como presidente John Paterson también cabeza del Standard Bank of British South Africa y como vicepresidente James L. Hart que fungía como vicecónsul de Londres en la ciudad de México. En el comité estaban otros expertos, y accionistas de la institu-

Sucursal, Y por Cuanto que pueda llegar á ser ójuzgarse ser necesario o expediente para que la dicha Compañía requiera del Emperador ó del Gobierno de México ciertos poderes y concesiones para la emisión de Billetes [...] nombra a Newbold como apoderado legal y verdadero para que a nombre de y por parte de la Compañía pueda practicar diligencias en los asuntos y demás cosas de la misma. Igualmente se le dio poder y autoridad para diligenciar y obtener predios, arrendarlos a plazos fijos o como fuere conveniente en el Imperio de México, asimismo amueblar las casas o predios, asimismo como recibir dineros y depósitos, girar, endosar, aceptar, descontar, negociar letras de cambio y pagarés a nombre del Banco, además de dirigir los negocios de Banca de costumbre. Podía demandar, enjuiciar para recobrar los pagos o adeudos pendientes, deudas, derechos, bienes, géneros, mercancías, muebles, y otros efectos. Del mismo modo podía aceptar u endosar cualquier le tra o letras de cambio, pagarés o vales y para firmar, endosar, aceptar, asignar o transferir toda letra o letras, o conocimientos u órdenes de entrega u otros símbolos o indicantes de mercancías, póliza o pólizas de seguro, contratos y cartas de fletamientos, certificados de buques, cartel o carteles de ventas (inventarios), Fondos públicos o del Gobierno". En AGN, Ignacio Cosio, Notario núm. 57, vol. 372, 1865. Manuscritos. Protocolización del poder conferido por los Directores del Banco de Londres, México y Sudamérica al señor don Guillermo Newbold, ff. 123v.-129. 
ción como William Walter Cargile, miembro de la Cámara Alta del Parlamento y directivo del Oriental Bank Corporation, Frederick Harrison también presidente del London and Country Bank, ${ }^{64}$ de Abel Heywood y Robert Rumney directores del Alliance Bank ligada a una de las compañías de seguros más importantes en Londres, así como de William A. Jones que había dirigido el Anglo-Mexican Mines Company ligada a la casa bancaria de Baring, a este organismo pertenecieron también Lewis Langworthy de la ciudad de Manchester, de William J. Marshall, presidente del London Bank of Scotland. Además, la empresa contaba con una agencia en la ciudad de París a cargo de la firma de Bischoffshein, Goldschmidtz y Cía., que le abrió al de Londres, México y Sudamérica un crédito por 20000 libras esterlinas. ${ }^{65}$

A través de un primer acercamiento a los fondos notariales de 1864, primer año de vida de la empresa, se aprecia la dinámica de los negocios que impusieron Newbold y Geddes al Banco de Londres, México y Sudamérica al autorizar la apertura de

[...] una cuenta de depósito en la cual figuraran por primera partida, los $\$ 5000$ que acaban de entregarnos. En esa cuenta les abonaremos intereses a razón del $6 \%$ al año. También les abriremos una cuenta activa, o sea cuenta corriente, en la cual sentaremos todos los pagos y cobros que hagamos por su cuenta. En esta última están ustedes facultados para disponer de una cantidad doble de la que tengan a su crédito en su cuenta de depósito, hasta la concurrencia de $\$ 20000$. Es decir que desde ahora pueden ustedes disponer hasta de $\$ 10000 \mathrm{y}$ cuando cuentan $\$ 10000$ al haber de la cuenta de depósito, pueden hacer uso de $\$ 20000$. Las condiciones de esta última cuenta serán las siguientes: cargaremos a ustedes en interés del $12 \%$ anual sobre las partidas a su débito, y les abonaremos

${ }^{64}$ Fue uno de los primeros bancos privados fundado por acciones ("joint stocks banks") fundado en 1836, que contó con una amplia red de agencias en la provincia inglesa, Banco de Londres y México, 1864, pp. 26-27.

${ }^{65}$ Firma inglesa con sede en Londres y París, y agente financiero de la filial en París en Banco de Londres y México, 1864, p. 32. 
$9 \%$ anual la a su rédito, cargándoles además una comisión de $1 / 4 \%$ sobre el lado mayor de la cuenta. ${ }^{66}$

El servicio se otorgó sobre todo a productores (panaderos y tocineros), a comerciantes de mediana talla y a propietarios de fincas rústicas o urbanas, algunos de ellos agricultores y otros profesionistas liberales, siendo excepcionales las operaciones por cantidades mayores de prósperos hacendados y compañías de minas.

En la casi totalidad de los casos, registrado en el cuadro siguiente, los individuos residían en la ciudad de México, y justificaban su petición en la necesidad de "fomentar sus negocios". Se trata de un contrato mercantil denominado "escritura de reconocimiento", por medio del cual el notario, además de referirse al monto de la operación, registraba el plazo convenido y las garantías que ofrecía el préstamo al banco, se trataba, en todos los casos, de la firma de pagarés o la entrega de libranzas, además de la escritura de la propiedad o de las propiedades cuando la cantidad fuera más alta. En el caso de no redimirse el título de pago en el plazo previsto se establecía que se pagaría $6 \%$ de interés, y en algunos casos se señalaba que la institución entregaba la cantidad solicitada por medio de un depósito o en letras de cambio pagaderas en Londres, en tanto que el particular se obligaba a retribuirle la cantidad en moneda fuerte de plata.

El éxito de las cuentas corrientes y la inmediata expansión de corresponsales y sucursales animó a los directivos del Banco de Londres, México y Sudamérica en abril de 1865 a imprimir y poner en circulación los primeros billetes con valor de cinco pesos y por un monto de 1400 pesos, habiendo ese año una nueva emisión de billetes con valor de 10,20 y 50 pesos, y un año más tarde comenzaron a circular billetes de más alta denominación equivalente a los 100 y 500 pesos. $^{67}$

${ }^{66}$ Un ejemplo de oficio citado en Banco de Londres, México y Sudamérica, 1964, p. 26.

${ }^{67}$ Banco de Londres y México, 1964, p. 26. 
FUNDACIÓN DE INSTITUCIONES DE CRÉDITO

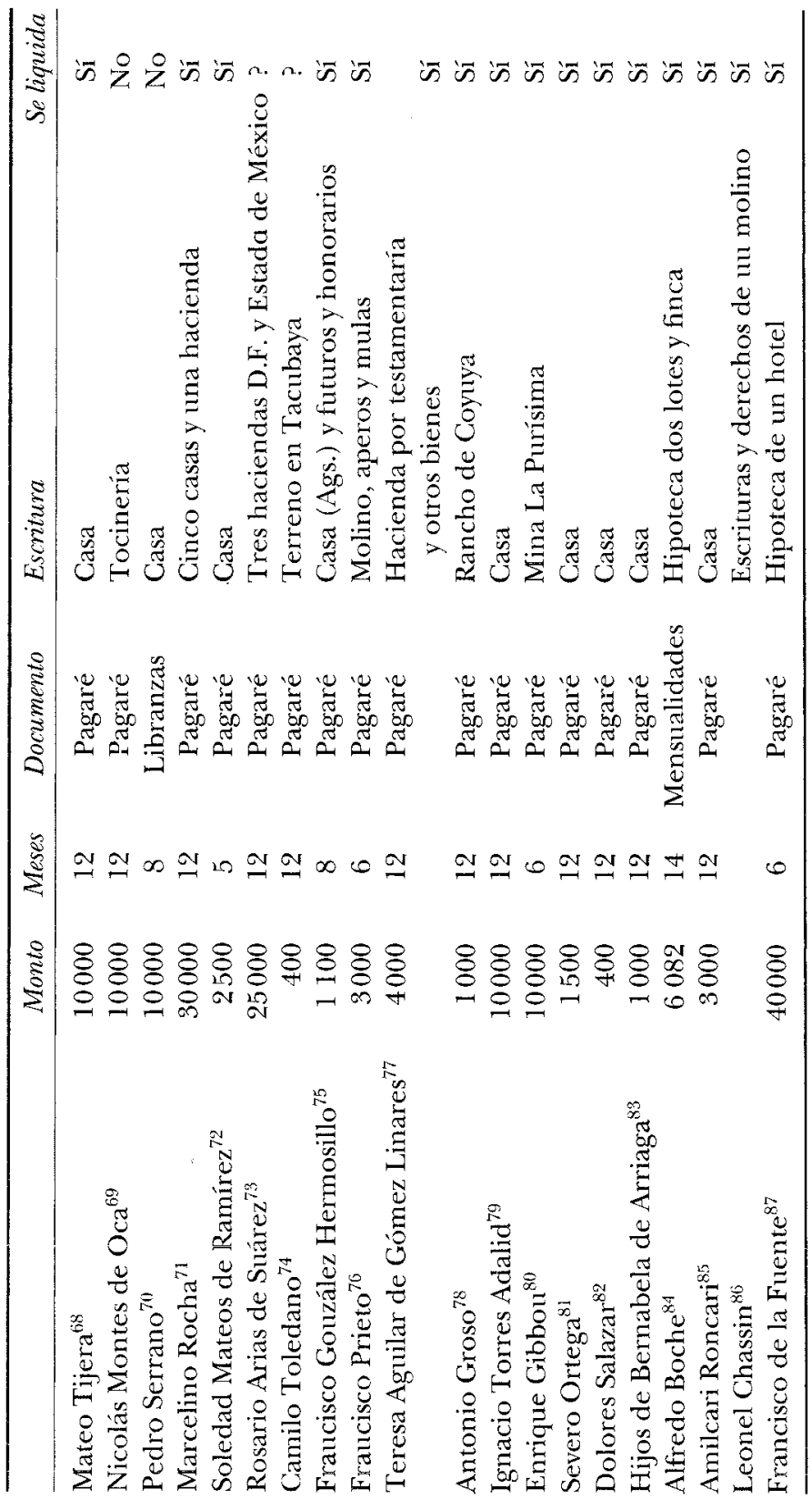


${ }^{68}$ Se precisa que es español, en AGN, Ignacio Cosío, Notario núm. 57 , 3 de agosto de 1864 , vol. 371 , ff. $225 \mathrm{v} .-227 \mathrm{v}$.

${ }^{69}$ AGN, Ignacio Cosío, Notario núm. 57, 5 de agosto de 1864, vol. 371 , ff. $227 \mathrm{v} .-230$ y fojas anexas.

${ }^{70}$ AGN, Ignacio Cosio, Notario núm. 57, 10 de agosto de 1864, vol. 371 , ff. 233-234v. y 237.

${ }^{71}$ Comerciante de Guanajuato, AGN, Ignacio Cosio, Notario núm. 57 , 13 de agosto de 1864, vol. 371, ff. 242v.-245v. y 248.

${ }^{72}$ AGN, Ignacio Cosio, Notario núm. 57, 13 de agosto de 1864, vol. 371 , ff. $248 \mathrm{v} .-250$.

${ }^{73}$ Se aclara que la operación se realiza con licencia que le otorgó su marido y que fue convenida por intermedio del corredor Simón Gutmann, además de que el banco le entregó la cantidad prestada en letras giradas sobre Londres (47 peniques por peso), y que se pagaría en moneda de plata fuerte, AGN, Ignacio Cosio, Notario núm. 57, 18 de agosto de 1864, vol. 371, ff. 251v.-254v. y 256.

${ }^{74}$ AGN, Ignacio Cosío, Notario núm. 57, 19 de agosto de 1864, vol. 371, ff. $256-258$.

${ }^{75}$ Se otorgó una prórroga hasta el 12 de noviembre de 1869, en AGN, Ignacio Cosio, Notario núm. 57, 20 de agosto de 1864, vol. 371, ff. 260v.$262 \mathrm{v}$.

${ }^{76}$ AGN, Ignacio Cosio, Notario núm. 57, 29 de agosto de 1864, vol. 371, ff. $278-279 v$.

${ }^{77}$ El banco le entregaría el dinero por depósito regular, se precisa además que el capital y los réditos tendrían que ser cubiertos en moneda de plata fuerte, de la ley de 10 dineros 20 granos. AGN, Ignacio Cosío, Notario núm. 57, 29 de agosto 1864, vol. 371, ff. 283v.-285.

${ }^{78}$ A pagar en moneda de plata fuerte, en AGN, Ignacio Cosio, Notario núm. 57, 29 de agosto de 1864, vol. 371, ff. 285-286v.

${ }^{79}$ AGN, Ignacio Cosío, Notario núm. 57, 30 de agosto de 1864, vol. 371 , ff. 292-294v. y 296.

${ }^{80}$ Inglés, solicita préstamo en representación de la Compañía de Minas de Guadalupe. El banco le entregaría el dinero por depósito regular, además se indica que se concedió prórroga de acuerdo con la petición de los accionistas: Enrique Gibbon, J. B. Jecker; Vicente Escandón, Ignacio Arróniz, Ignacio Fuentes, Pablo Bonfil, Juan Ricardo Rule, Bruno de Ordovilla, Rafael Beraza y Pedro Rincón, en AGN, Ignacio Cosio, Notario núm. 57,31 de agosto de 1864, vol. 371, ff. 301-302 y dos fojas anexas.

${ }^{81}$ AGN, Ignacio Cosio, Notario núm. 57, 2 de septiembre de 1864, vol. 371 , ff. 305 306 .

${ }^{82}$ AGN, Ignacio Cosío, Notario núm. 57, 6 de septiembre de 1864, vol. 371, ff. 311-313.

${ }^{83}$ AGN, Ignacio Cosío, Notario núm. 57, $1^{\circ}$ de octubre de 1864, vol. 371 , ff. $344 v-358$.

${ }^{84}$ Súbdito francés, por vía de depósito irregular, y se cubriría con moneda de plata fuerte, en AGN, Ignacio Cosio, Notario núm. 57, del 6 de octubre de 1864, vol. 371, ff. 355v.-358. 
A pesar de la situación reinante, el Banco continuó sus operaciones, facilitando dinero a empresas metalúrgicas (De las Delicias de Gustavo A. Beaurang) y de textiles de lana (Hércules en Querétaro, de Cayetano Rubio) o en la venta de algodón mexicano en Londres a través de Matamoros y Tampico, así como en otras firmas, cervecerías y mercantiles. Además de participar activamente en el comercio de títulos de crédito gubernamental como fueron los documentos que adquirió de las Convenciones española e inglesa, estos últimos pertenecientes a connotados prestamistas como Pablo Martínez del Río, José C. Murphy, Manuel J. Lizardi, José de Anzoátegui, J. A. de Béistegui, todos ellos de la empresa de tabaco así como del agente de la firma londinense de Baring, Eduardo J. Perry entre otros acreedores, que traspasaron sus documentos al banco con el fin de que los negociase ante el gobierno, operación a la que se sumaron futuros empresarios de la generación siguiente como el minero Félix Cuevas y el comerciante veracruzano $\mathrm{H}$. de Viya. ${ }^{8}$

A fines de ese año se había roto el frágil equilibrio militar y financiero que había alcanzado el segundo imperio y la oposición fue en aumento. De una parte, las fuerzas conservadoras y algunos moderados adictos al régimen lo abandonaron como resultado de la política secular de Maximiliano y de la imposibilidad de que este régimen y el reacio Vaticano de Pío IX, se pusieran de acuerdo en los términos del proyectado concordato. A esta debilidad interna del gobierno imperial se sumaba la nueva ofensiva

${ }^{85}$ Súbdito italiano, se anota que el crédito se traspasó al repostero italiano Lorenzo Fulcheri. AGN, Ignacio Cosio, Notario núm. 57, 9 de noviembre de 1864, vol. 371, ff., 397-398v. Esta última operación fue realizada el 20 agosto de 1866, en vol, 379, ff. 382v.-384v.

${ }^{86}$ Docior francés, se comprometió Chassin a que si existía haber en favor del banco, lo pagaría en moneda de plata fuerte. En caso de no cumplir, el banco podría disponer de la escritura. AGN, Ignacio Cosio, Notario núm. 57, 5 de diciembre de 1864, vol. 371, ff. 413v. y 415v.

${ }^{87}$ Español vecino, se le otorgó la cantidad por vía de depósito irregular. AGN, Ignacio Cosio, Notario núm. 57, 15 de diciembre de 1864, vol. 371 , ff. $428-430 \mathrm{v}$. y 433 .

${ }^{88}$ Banco de Londres y México, 1964, pp. 31-32. 
liberal tras la terminación de la guerra de secesión estadounidense que se acompañó del apoyo del gobierno de Lincoln a las fuerzas liberales, lo que permitió al presidente Juárez reinstalar su gobierno en agosto de 1865 en Paso del Norte (hoy Ciudad Juárez).

El giro en la vida política debilitó al gabinete de Maximiliano y reforzó a las tropas del general Bazaine que se apoderó de los exiguos recursos del Tesoro imperial para pagar a los ejércitos franceses. Al interior del país se desvanecían las promesas de la aventura imperial, por lo que en enero de 1866 Bonaparte optó por abandonar a Maximiliano con el fin de concentrar sus energías en Europa reforzando su alianza con Austria en lucha contra el naciente poderío prusiano, ${ }^{89}$ en tanto que los capitales franceses ya dirigian sus tropas invasoras y sus recursos pecuniarios a zonas más prometedoras (Egipto, Túnez y Turquía) o simplemente optaban por invertir en la construcción ferroviaria y en la apertura de empresas bancarias en países vecinos, como España e Italia. Conflictos de intereses que marcaron una parte importante del fracaso del régimen de Maximiliano, a la vez que Bonaparte perdía progresivamente a sus principales aliados financieros y militares en Europa. Ante tal situación Bonaparte no dudó en ordenar el retiro de los ejércitos franceses de tierras mexicanas, no obstante las presiones que hizo el general Almonte ante su gabinete y de las propuestas financieras que ofrecieron los representantes mexicanos a banqueros parisinos a nombre de Maximiliano. ${ }^{90}$

El fin del segundo imperio se aceleró hacia mediados del año de 1866, y entre las filas de la élite del dinero de la

${ }^{89}$ Los cambios en la geopolítica alteraron la situación que el segundo imperio tenía en 1862, cuatro años más tarde Prusia y Austria se habian unido, Italia había logrado llevar a cabo su unificación a pesar de la oposición del emperador, e Inglaterra y Rusia optaron por una política aislacionista que los mantenía fuera de las tensiones europeas. GirARAD, 1986, pp. 376-377.

${ }^{90}$ Se conoció como Convención del 30 de julio de 1866, y en ella se ofrecía en tregar a Francia la mitad de los ingresos aduanales, en LEFÉBre, 1869 , pp. 336-338. 
ciudad de México muchos optaron por apoyar a las filas liberales, cuyos ejércitos avanzaron exitosamente en dirección a la capital. Una vez que el gobierno de Estados Unidos acompañó de un préstamo de 20000000 de pesos el reconocimiento al gobierno del presidente Benito Juárez, decisión que fue seguida del retiro de los ejércitos del general Bazaine del territorio mexicano. Acontecimientos que aceleraron la abdicación de Maximiliano, y permitieron a los comercios prusiano y español tomar a su cargo el manejo administrativo de la ciudad y situarse en la delantera de los negocios, al momento en que las fuerzas liberales entraron triunfantes a la capital mexicana.

Tras el fusilamiento de Maximiliano se dejó a un lado el problema de la deuda pública convenida desde el periodo independiente, algunos acreedores internos de la era del agio habían fallecido y otros tuvieron que gestionar ante las autoridades republicanas la legitimidad de sus protestas que debieron ser consideradas como deuda interna. En tanto que los reclamos de los tenedores extranjeros hubieron de esperar varios años a causa del rompimiento de relaciones diplomáticas entre México y sus gobiernos.

Hacia fines de los años 1860 surgieron los nuevos financieros de las fuerzas republicanas, que de inmediato recibieron como pago de sus créditos, fincas rústicas y urbanas que años antes eran propiedad de instituciones eclesiásticas, varios de ellos formaban parte de las comunidades de residentes europeos que fueron en aumento desde mediados de siglo y cuyo patrimonio provino fundamentalmente del universo mercantil, cuyo dinamismo era producto del crecimiento de las ciudades y de su relación con los ejércitos liberales dueños de los espacios mercantiles durante los años de la guerra.

La incorporación de esos nuevos miembros a la élite del dinero de la capital mexicana, se ajustó de inmediato a los cambios introducidos en la vida administrativa y mercantil del periodo imperial que se preservaron en la etapa siguiente, pero la consolidación de estos sectores dependió del favorecimiento de las camarillas políticas en pugna encabezadas por Sebastián Lerdo de Tejada y Porfirio Díaz. 


\section{SIGLAS Y'REFERENCIAS}

AGN Archivo General de la Nación, México.

AGNM Archivo General de Notarías de la Ciudad de México, México.

Arnatz y Freg A. y Claude Batail.lon

1965

La intervención francesa y el Imperio de Maximiliano. Cien años después. México: Asociación Mexicana de Historiadores-Instituto Francés de América Latina.

Arnaud

1891

Les barcelonnettes au Mexique. Extraits des documents et considérations historiques sur la vallée de Barcelonnette, s.e.

Arrangorz, Francisco de Paula de

1968 México desde 1808 hasta 1867. México: Porrúa.

Banco de Londres y México

1864 Banco de Londres y México, 100 años de su fundación. México.

Barbier, Frédéric

1991

Finance et politique. La dynastie des Fould, $x w m \dot{\dot{e}}-x x^{\dot{\imath}}$ siècle. Paris: Armand Colin.

BAZANT, Jan

1981

Historia de la deuda exterior de México, 1823-1946. México: El Colegio de México.

Bonin, Hubert

1991

L'argent en France depuis 1880. Banquier, financiers et épargnants. Paris: Masson, Collection.

Bouvier, Jean

1992

Les Rothschild. Histoire d'un capitalisme familial. Bruselas: Éditions Complexe.

CADiER, Gabrielle

1991 "Les consequénces du Traité de 1860 sus les échanges franco britanniques", en Crouzet, pp. 205-212.

Cassis, Youssef:

1987

La City de Londres, 1870-1914. Paris: Librairie Blenin.

Conte Cortin, Egon Caesar

1944 Maximiliano y Carlota. México: Fondo de Cultura Económica. 
Cottrel, Philip L.

1984

Historia politica de Inglaterra. México: Fondo de Cultura Económica.

Crovzet, François M. (coord.)

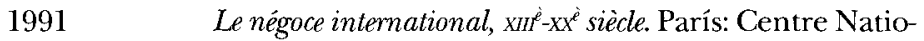
nal des Lettres, Economica.

Chapman, John Gresham

1975

La construcción del ferrocarril mexicano (1837-1880). México: Secretaría de Educación Pública.

Chevaluer, François

1965

"Conservateurs et liberaux au Mexique, Essai de sociologie et geographie politique de l'independance à l'intervention française", en Arnatz y Freg y BatalLLON, pp. 9-25.

Chevaluer, Michel

1863

Le Mexique Ancien et Moderne. Paris: Librairie del Hachette et Cíe.

Davidson, N.

1864 Apuntes sobre el establecimiento de un Banco Nacional en México. México: Imprenta de Andrade y Escalante.

GiLLE, Bertrand

1970

La Banque en France au xix ìme siècle, Recherches historiques. París-Ginebra: Droz.

GILLE, Geneviève

1965

"Les capitaux français et l'expedition du Mexique", en Revue d'Histoire Diplomatique, 69 (jul.-sep.), pp. 193-250.

Girarad, Louis

1986

Napoleón III. París: Librairie Arthème Fayard.

Labastida, Luis G.

1989

Estudio Histórico y filosófico sobre la legislación de los bancos. Edición facsimilar de 1889. México: Miguel Ángel Porrúa-Banco Nacional del Pequeño Comercio.

LEFÊBRE, E.

1869 Documentos óficiales recogidos en la Secretaria privada de Maximiliano. Historia de la intervención francesa en Méjico. Bruselas y Londres, vol. ir. 
Lévy Léboyer, Maurice

1977 La position internationale de la France. Aspects économiques et financiers, $\mathrm{xIX}$ et $\mathrm{xx}$ siècles. Paris: Editions de l'Ecole des Hautes Études en Sciences Sociales.

Lublow, Leonor

1986 La construcción de un Banco: el Banco Nacional de México, 1880-1884", en Lldoow y Marıchal, pp. 299-345.

1990 "El Banco Nacional Mexicano y el Banco Mercantil Mexicano: radiografía social de sus primeros accionistas, 1881-1882", en Historia Mexicana, xxxix:4 (156) (abr.-jun.), pp. 979-1028.

1995 "Las dinastías financieras en la ciudad de México. De la libertad comercial a la reforma liberal". Tesis de doctorado en ciencias sociales. México: El Colegio de Michoacán.

Ludlow, Leonor y Carlos Marichal

1986 Banca y poder en México, 1800-1926. México: Grijalbo.

Ludlow, Leonor y Jorge Srlva-Riguer

1993 Los negocios y las ganancias de la Colonia al México moderno. México: Instituto de Investigaciones Dr. José María Luis Mora-Instituto de Investigaciones Sociales, Universidad Nacional Autónoma de México.

Maillefert, Eugenio

1992

Directorio del comercio del Imperio Mexicano. Edición facsimilar. México: Instituto Dr. José María Luis Mora.

MiCHEL, Bernard

1977

"Les capitaux français en Autriche au début du xrx ${ }^{c}$ siècle", en LÊVY LébOYER, p. 228-233.

Payno, Manuel 1980

Cuentas, gastos, acreedores y otros asuntos del tiempo de la Intervención francesa y el Imperio. Obra escrita y publicada por orden del Gobierno Constitucional de la República por... De 1861-1867 (edición facsimilar de 1868). México: Miguel Ángel Porrúa.

1982

México y sus cuestiones financieras con la Inglaterra, la España y la Francia. Edición facsimilar. México: Secre- 
taría de Hacienda y Crédito Público-Miguel Ángel Porrúa.

1982a Cuentas, gastos y acreedores. Edición facsimilar. México: Secretaría de Educación Pública-Miguel Ángel Porrúa.

Puessis, Alain

1979

De la fête imperiale au mur des fédérés, 1852-1871. París: Points-Histoire du Seuil.

Rrvera Cambas, Manuel

1987

Historia de la Intervención Europea y Norteamericana en México y del Imperio de Maximiliano de Habsburgo. (Edición facsimilar 1888.) México: Instituto Nacional de Estudios Históricos de la Revolución Mexicana, vol. II.

Torik, Steven C.

1993

"Controversia crediticia: los "azulitos" del periodo de Maximiliano", en Ludlow y Silva-Riguer, pp. 445-470. 